\title{
REVIEW
}

\section{Plasma-free amino acid profiles are predictors of cancer and diabetes development}

\author{
$\mathrm{X} \mathrm{Bi}{ }^{1}$ and CJ Henry ${ }^{1,2}$
}

Type 2 diabetes (T2D) and cancers are two major causes of morbidity and mortality worldwide. Nowadays, there is convincing evidence of positive associations between T2D and the incidence or prognosis of a wide spectrum of cancers, for example, breast, colon, liver and pancreas. Many observational studies suggest that certain medications used to treat hyperglycemia (or T2D) may affect cancer cells directly or indirectly. The potential mechanisms of the direct T2D cancer links have been hypothesized to be hyperinsulinemia, hyperglycemia and chronic inflammation; however, the metabolic pathways that lead to T2D and cancers still remain elusive. Plasma-free amino acid (PFAA) profiles have been highlighted in their associations with the risks of developing T2D and cancers in individuals with different ethnic groups and degree of obesity. The alterations of PFAAs might be predominately caused by the metabolic shift resulted from insulin resistance. The underlying mechanisms have not been fully elucidated, in particular whether the amino acids are contributing to these diseases development in a causal manner. This review addresses the molecular and clinical associations between PFAA alterations and both T2D and cancers, and interprets possible mechanisms involved. Revealing these interactions and mechanisms may improve our understanding of the complex pathogenesis of diabetes and cancers and improve their treatment strategies.

Nutrition \& Diabetes (2017) 7, e249; doi:10.1038/nutd.2016.55; published online 13 March 2017

\section{INTRODUCTION}

Diabetes mellitus (DM) and cancer are two severe chronic diseases with tremendous impact on global health. Epidemiologic studies have shown that several forms of cancers, such as liver, pancreas, endometrium, colorectal, breast and bladder, develop more frequently in patients with diabetes. ${ }^{1,2}$ Diabetes (primarily type 2, T2D) and cancers share many common risk factors, for example, aging, physical inactivity, diet and obesity. The potential biologic links between these two diseases are yet incompletely understood but may involve insulin resistance. ${ }^{3}$

Insulin resistance, intertwined with hyperinsulinemia, has been suggested as one of the possible underlying mechanisms for the direct connection between T2D and cancers. ${ }^{3}$ T2D is typically preceded by hyperinsulinemia to maintain glucose homeostasis. ${ }^{4}$ Additionally, convincing evidence have suggested that hyperinsulinemia may affect the signaling pathways of insulin and insulin-like growth factor 1 (IGF-1) and thus facilitate cancer development and progression. ${ }^{5}$ The etiology of insulin resistance has been either focused on lipid-mediated mechanisms ${ }^{6}$ or the interplay with obesity, which induces metabolic abnormalities. ${ }^{7}$ The latter is partly reflected in the abnormal circulating levels of lipid, protein and other classes of metabolites. Among the numerous metabolites, amino acids may have potential as excellent disease biomarkers because they are involved in protein synthesis and as metabolic regulators. ${ }^{8}$ In 1969, hyperaminoacidemia, manifested by elevated plasma-free amino acids (PFAAs) including branched-chain amino acids (BCAAs), that is, valine (Val), leucine (Leu), isoleucine (lle) and aromatic amino acids (AAAs), that is, tyrosine (Tyr) and phenylalanine (Phe) in obese subjects, was reported. ${ }^{9}$ Hyperaminoacidemia in obesity may be a manifestation of increased insulin resistance.

Insulin has long been recognized as the regulator of branchedchain alpha-keto acid dehydrogenase complex, an enzyme complex involved in BCAA catabolism. ${ }^{10}$ Insulin resistance has been found to reduce the enzymatic activity of branched-chain alpha-keto acid dehydrogenase complex and hence suppress BCAA catabolism. This is considered as the plausible etiology of increased BCAA levels in obesity and/or diabetes. ${ }^{11}$ Indeed, evidence is accumulating that there is positive association between insulin resistance and circulating concentrations of BCAAs. ${ }^{12-15}$ In addition, insulin resistance was shown to be correlated with the alterations of several other PFAAs, including AAAs, alanine (Ala), proline (Pro) and glycine (Gly). ${ }^{16}$

In recent years, PFAA profiles were found to be significantly altered in patients with diabetes and/or cancers. ${ }^{17-21}$ Little is known about the mechanisms, particularly whether PFAAs are contributing to the development of these diseases in a causal manner. However, the altered PFAA profiling appears to provide a great diagnostic potential and could be a promising biomarker for understanding the etiology and pathogenesis of diabetes and cancers. $^{22}$

\section{ALTERED PFAA PROFILES IN CANCER PATIENTS}

Cancer cells require certain amino acids, for example, glutamine (Gln), Gly, aspartic acid (Asp) and serine (Ser), for DNA synthesis, building new blood vessels, and duplicating their entire protein contents. ${ }^{23}$ They also require amino acids for proteins synthesis.

\footnotetext{
${ }^{1}$ Clinical Nutrition Research Centre (CNRC), Singapore Institute for Clinical Sciences (SICS), Agency for Science, Technology and Research (A*STAR), Singapore, Singapore and ${ }^{2}$ Department of Biochemistry, Yong Loo Lin School of Medicine, National University of Singapore, Singapore, Singapore. Correspondence: Professor CJ Henry, Clinical Nutrition

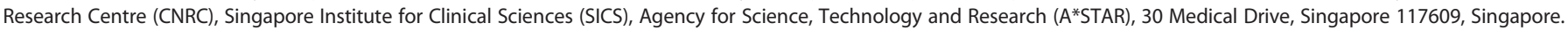
E-mail: jeya_henry@sics.a-star.edu.sg

Received 2 October 2016; revised 17 November 2016; accepted 24 November 2016
} 
These proteins work as growth-promoting hormones or tumor growth factors. ${ }^{24,25}$ The increase in the amino acid demand may thus lead to a lower availability of PFAAs in cancer patients. ${ }^{26}$ Table 1 summarizes twenty studies specifically addressed the alterations of circulating amino acid concentrations in different cancer patients.

Vissers et al. $^{27}$ analyzed the PFAA concentrations in three types of cancer patients with different levels of weight loss, that is, breast cancer (without weight loss), colonic cancer (occasional weight loss) and pancreatic cancer (frequent weight loss). They found a significant decrease in arginine (Arg) levels, regardless of tumor types and stages, weight loss or body mass index. This finding suggested that decreased Arg availability was a specific feature of the presence of a malignant tumor. They also revealed that BCAA concentrations were lower in all cancer patients than in age- and sex-matched controls; whereas TAAs were lower only in pancreatic cancer patients. It should be noted that the alterations of PFAA levels depend on the stage and the type of cancers. The study conducted by Gu et al. ${ }^{28}$ examined the PFAA profiles in 56 patients with gastric cancer, 28 patients with breast cancer, 33 patients with thyroid cancer and 137 healthy controls which were age matched. It was found that histidine (His) level was significantly decreased in breast cancer patients. Levels of Ser, Ala, Val, lysine (Lys), His, BCAAs, and TAAs were significantly decreased in gastric cancer patients. However, the thyroid cancer patients had significantly increased levels of methionine (Met), Leu, Tyr and Lys (Table 1). Besides the different types of cancers, the variation of PFAA pattern of patients was due to the different disease stages. Most of the patients with breast cancer or thyroid cancer in this study were characterized as early stage, whereas 12 of gastric cancer patients were characterized as advanced stage (stage IV). This study also showed that Ala, Arg, Asp and cysteine (Cys) promoted the proliferation of breast cancer cells. Alternatively, Cys promoted the proliferation of gastric cancer cells, but Ala and glutamic acid (Glu) inhibited it. These results underscored the potential function of the assessment of tumor-related PFAA patterns to examine and diagnose various cancers.

Recently, Aminolndex Cancer Screening (AICS) technology was employed as a novel cancer risk calculation method for early stage cancer diagnosis. ${ }^{21,29,30,45,46}$ In order to build AICS, 19 amino acids including threonine (Thr), asparagine (Asn), Ser, Gln, Pro, Gly, Ala, citrulline (Cit), Val, Met, Ile, Leu, Tyr, Phe, His, tryptophan (Trp), ornithine (Orn), Lys and Arg, were measured and statistically analyzed. For the colorectal cancer risk calculation in one case report, ${ }^{21}$ plasma levels of Ser, Pro, Val, Met, lle and Lys were used. The AICS score was found to be 8.3 , which indicated that the patient had an $\sim 10$-fold-increased risk of cancer. When the patient underwent colonscopy, a 10-mm adenoma-like lesion in the ascending colon with partial carcinoma was observed. The early detection of carcinoma using AICS method allowed complete resection, suggesting that PFAA profiles may provide a fast and easy diagnostic tool for cancers. Another study conducted by Fukutake et al. ${ }^{20}$ used Ser, Asp, Ile, Ala, His and Trp as variables to calculate the pancreatic cancer risk and successfully discriminate patients with pancreatic cancer $(n=360)$ from control subjects $(n=8372)$. They also analyzed the levels of 19 amino acids and a significant increase in Ser level and significant decreases in the levels of Thr, Asn, Pro, Ala, Cit, Val, Met, Leu, Tyr, Phe, His, Trp, Lys and Arg were observed in pancreatic cancer patients. Several other studies with small sample size ${ }^{37,38}$ reported similar decreases in circulating amino acid levels in pancreatic cancer patients, which was interpreted as a result of the enhanced usage of PFAAs in tumors. Another possibility for the decreased levels of amino acids was associated with malnutrition. Patients with pancreatic cancer are usually troubled by malnutrition due to exocrine pancreatic insufficiency (EPI).

However, some studies investigating amino acid levels in plasma or serum samples from patients with breast cancer showed contradictory results (Table 1 ). Poschke et al. ${ }^{31}$ reported increased levels of Glu, Ser, Gln, Ala, Val, Phe, lle and Leu in 41 breast cancer patients. One possible explanation could be that the stage of tumor in this study population was categorized as early stage such that it did not reduce the amino acid pool. The increased level of Ser was probably due to the increased enzymatic activity involved in Ser biosynthesis in tumor cells. ${ }^{47}$ The increased levels of Glu and Ala may be produced by tumor cells. ${ }^{48}$ Similar increment of amino acid levels, that is, Orn, Glu and Trp in breast cancer patients, was observed previously. ${ }^{49}$ However, other study demonstrated a decrease of Gln, Tyr, Phe, His and Trp, whereas an increase of Thr, Ser, Pro, Gly, Ala, Orn and Lys, in 196 patients with breast cancer. ${ }^{29}$ The above mentioned contradictory results might be attributed to the differences in participant characteristics, including age, gender, ethnic background, diet, and countries where participants live, different measurement techniques applied for PFAA profiles, different diseases stage, and lack of data adjustment for potential confounders. Meanwhile, PFAA profiles may be affected by various factors, including the amount and/or composition of dietary protein, metabolism of muscle protein, as well as the labile protein reserve in different tissues.

\section{MECHANISM UNDERLYING ALTERATIONS OF PFAA PROFILES}

Table 1 shows that patients with cancers have altered PFAA profiles. Apparently, the pattern and degree of the alterations depend on the type of cancer and the disease stage. Determination of the precise mechanism underlying changes in the PFAA profiles has the great potential for cancer diagnosis and treatment. Various recent studies tried to find out the connections between cancers and specific PFAA profiles (Table 2). Among all of the amino acids, Gln has attracted great attentions as cancer cells are known to be avid consumers of Gln. ${ }^{50,51}$ Building on the Warburg effect, ${ }^{52}$ cancer cells extensively use Gln to produce ATP (adenosine-triphosphate) to sustain anabolism, which is necessary for tumor growth and proliferation. It has been demonstrated that breast cancer cell lines expressing high levels of c-MYC were dependent on GIn for their survival and growth. ${ }^{53}$ As shown in Table 1, significant decrease of Gln was observed in patients with pancreatic cancer, ${ }^{27,38}$ Lung cancer, gastric cancer, colorectal cancer, breast cancer and prostate cancer. ${ }^{29}$ On the other hand, the increased Glu levels in colorectal cancer patients ${ }^{30}$ and breast cancer patients ${ }^{30-32}$ could also be interpreted as the result of increased Gln metabolism in tumor cells. Although Gln consumption is increased in most tumors, some cancer cells can survive and proliferate by relying on glucose without $\mathrm{Gln}^{54}$

Gly and Ser are biosynthetically linked, both of which are classic metabolites of glycolysis. The biosynthesis pathway of Ser utilizes the glycolysis intermediate 3-phosphoglycerate, which is converted by phosphoglycerate dehydrogenase, phosphoserine aminotransferase and phosphoserine phosphatise into Ser. In Gly metabolism, Gly is converted to methylenetetrahydrofolate by glycine decarboxylase. Meanwhile, serine hydroxymethyltransferase converts Ser to Gly reversibly, linking the respective pathways of metabolism. Jain et $a .^{55}$ reported that Gly biosynthetic pathway was closely linked to cancer cell proliferation. A significant correlation between Gly consumption and cancer cell proliferation was observed, suggesting that Gly uptake and catabolism was able to promote tumourigenesis and malignancy. Additionally, emerging evidence suggested that aberrant activation of the biosynthetic pathway of Ser was an essential process in cancer pathogenesis. ${ }^{56}$ According to previous studies, glycine decarboxylase is highly expressed in several human cancers, including ovarian cancer, ${ }^{55}$ non-small-cell lung carcinoma ${ }^{57}$ and breast cancer. ${ }^{58}$ Phosphoglycerate dehydrogenase (the key enzyme for Ser biosynthesis) expression is normally upregulated in breast cancer and melanoma. ${ }^{59}$ As summarized in Table 1, Gly 
Table 1. Summary of 20 studies on PFAA profiles in cancer patients (from 2005 to 2015)

\begin{tabular}{|c|c|c|c|c|c|}
\hline First author & Year & Disease groups & $\mathrm{n}$ & PFAA profiles & Main conclusions \\
\hline Gu et $a l^{28}$ & 2015 & $\begin{array}{l}\text { Gastric cancer } \\
\text { Breast cancer } \\
\text { Thyroid cancer }\end{array}$ & $\begin{array}{l}56 \\
28 \\
33\end{array}$ & $\begin{array}{l}\text { Thr, Cys, Arg, EAAs } \uparrow \\
\text { Asp, Ser, Glu, Gly, Ala, Val, Lys, His, } \\
\text { Pro, NEAAs, BCAAs, TAAs } \downarrow \\
\text { Thr, Arg, EAAs } \uparrow \\
\text { Asp, Glu, Gly, His, Pro, NEAAs } \downarrow \\
\text { Thr, Met, Leu, Tyr, Lys, Arg, EAAs } \uparrow \\
\text { Asp, Glu, Gly, Pro, NEAAs } \downarrow\end{array}$ & $\begin{array}{l}\text { PFAA patterns in cancer patients } \\
\text { are altered perioperatively. }\end{array}$ \\
\hline Miyagi et al. ${ }^{29}$ & 2011 & $\begin{array}{l}\text { Lung cancer } \\
\text { Gastric cancer } \\
\text { Colorectal cancer } \\
\text { Breast cancer } \\
\text { Prostate cancer }\end{array}$ & $\begin{array}{l}200 \\
199 \\
199 \\
196 \\
134\end{array}$ & $\begin{array}{l}\text { Ser, Pro, Gly, Ile, Leu, Phe, Orn } \uparrow \\
\text { Asn, Gln, Cit, His, Trp } \downarrow \\
\text { Thr, Asn, Gln, Ala, Cit, Val, Met, Ile, } \\
\text { Leu, Tyr, Phe, His, Trp, Lys, Arg } \downarrow \\
\text { Thr, Asn, Gln, Cit, Val, Met, Leu, Tyr, } \\
\text { Phe, His, Trp, Orn, Lys, Arg } \downarrow \\
\text { Thr, Ser, Pro, Gly, Ala, Orn, Lys } \uparrow \\
\text { Gln, Tyr, Phe, His, Trp } \downarrow \\
\text { Thr, Ser, Pro, Gly, Ala, Orn, Lys } \uparrow \\
\text { Gln, Val, Leu, Trp, Arg } \downarrow\end{array}$ & $\begin{array}{l}\text { PFAA profiling had great } \\
\text { potential for cancer screening } \\
\text { and diagnosis. }\end{array}$ \\
\hline Okamoto et al. ${ }^{30}$ & 2009 & $\begin{array}{l}\text { Colorectal cancer } \\
\text { Breast cancer }\end{array}$ & $\begin{array}{l}49 \\
45\end{array}$ & $\begin{array}{l}\text { Glu } \uparrow \\
\text { Thr, Cit, Val, Met, Ile, Leu, Tyr, Phe, } \\
\text { EAAs, BCAAs } \downarrow \\
\text { Thr, Ser, Glu, aAba, Orn } \uparrow \\
\text { Met, Ile, Phe, Arg } \downarrow\end{array}$ & $\begin{array}{l}\text { The development of a cancer } \\
\text { alters PFAA profiles without } \\
\text { cachexia or weight loss. }\end{array}$ \\
\hline Poschke et al. ${ }^{31}$ & 2013 & Breast cancer & 41 & Glu, Ser, Gln, Ala, Val, Phe, lle, Leu $\uparrow$ & $\begin{array}{l}\text { Increased amino acid levels } \\
\text { correlated with pro- } \\
\text { inflammatory state and intrinsic } \\
\text { tumor subtype. }\end{array}$ \\
\hline Barnes et al. ${ }^{32}$ & 2014 & Breast cancer & 8 & $\begin{array}{l}\text { Glu, His } \uparrow \\
\text { Thr, Tau, Leu } \downarrow\end{array}$ & $\begin{array}{l}\text { The altered PFAA profiles may be } \\
\text { related to metabolic } \\
\text { perturbations associated with } \\
\text { breast cancer. }\end{array}$ \\
\hline Shingyogi et al. ${ }^{34}$ & 2013 & Lung cancer & 171 & $\begin{array}{l}\text { Pro, Orn } \uparrow \\
\text { His } \downarrow\end{array}$ & $\begin{array}{l}\text { PFAA profiling has great } \\
\text { potential for early detection of } \\
\text { lung cancer. }\end{array}$ \\
\hline Zhao et al. $^{35}$ & 2014 & Lung cancer & 27 & $\begin{array}{l}\text { Phe, Asp, Hyl } \uparrow \\
\text { Trp, Gly, Cit, Orn, Pro } \downarrow\end{array}$ & $\begin{array}{l}\text { PFAAs can be used to detect } \\
\text { lung cancer patients due to their } \\
\text { stronger correlation with cancer } \\
\text { tissue free amino acids. }\end{array}$ \\
\hline Kim et al. ${ }^{36}$ & 2015 & Lung cancer & 72 & $\begin{array}{l}\text { Pro, lle, Phe, Orn } \uparrow \\
\text { Thr, Cit, His, Trp } \downarrow\end{array}$ & $\begin{array}{l}\text { In the early stages (I and II), } \\
\text { significant decreases in the } \\
\text { relative levels of Thr, Cit, His and } \\
\text { Trp and increases in Pro and Ile. } \\
\text { Significant increases in Phe and } \\
\text { Orn during the late stages } \\
\text { (III and IV). }\end{array}$ \\
\hline Fukutake et al. ${ }^{20}$ & 2015 & Pancreatic cancer & 360 & $\begin{array}{l}\text { Ser } \uparrow \\
\text { Thr, Asn, Pro, Ala, Cit, Val, Met, Leu, } \\
\text { Tyr, Phe, His, Trp, Lys, Arg } \downarrow\end{array}$ & $\begin{array}{l}\text { PFAA index was developed and } \\
\text { validated for detection of } \\
\text { pancreatic cancer. }\end{array}$ \\
\hline Schrader et al. ${ }^{37}$ & 2009 & Pancreatic cancer & 12 & $\begin{array}{l}\text { Thr, Val, Trp, Lys, Asp, Ala, Arg, Tau, } \\
\text { Cit, EAAs, NEAAs, TAAs } \downarrow\end{array}$ & $\begin{array}{l}\text { A significant deficit in circulating } \\
\text { amino acid levels in pancreatic } \\
\text { cancer patients. }\end{array}$ \\
\hline Kobayashi et al. ${ }^{38}$ & 2013 & Pancreatic cancer & 43 & $\begin{array}{l}\text { Val, Thr, Met, Asn, Gln, Lys, His, } \\
\text { Tyr } \downarrow\end{array}$ & $\begin{array}{l}\text { Amino acid profiles and other } \\
\text { metabolomics can be used as a } \\
\text { diagnostic method for } \\
\text { pancreatic cancer. }\end{array}$ \\
\hline
\end{tabular}


Table 1. (Continued)

\begin{tabular}{|c|c|c|c|c|c|}
\hline Ma et al. ${ }^{39}$ & 2014 & $\begin{array}{l}\text { Esophageal } \\
\text { cancer }\end{array}$ & 51 & $\begin{array}{l}\text { Asp, Cys } \uparrow \\
\text { Glu, Gly, His, Thr, Tau, Ala, Met, Ile, } \\
\text { Leu, Phe } \downarrow\end{array}$ & $\begin{array}{l}\text { PFAA profiles in esophageal } \\
\text { cancer patients are significantly } \\
\text { different from those in controls. }\end{array}$ \\
\hline Zhang et al. ${ }^{40}$ & 2012 & $\begin{array}{l}\text { Esophageal } \\
\text { cancer }\end{array}$ & 67 & $\begin{array}{l}\text { Gln, Lys } \uparrow \\
\text { Val, Leu/lle, Met, Tyr, Trp } \downarrow\end{array}$ & $\begin{array}{l}\text { Metabolic profiles can } \\
\text { distinguish esophageal cancer } \\
\text { patients. }\end{array}$ \\
\hline Yatabe et al. ${ }^{21}$ & 2013 & Colorectal cancer & Case report & $\begin{array}{l}\text { High plasma level of Ile and low } \\
\text { level of Ser }\end{array}$ & $\begin{array}{l}\text { An early stage of colon } \\
\text { carcinoma is found from PFAA } \\
\text { distribution. }\end{array}$ \\
\hline Leichtle et al. ${ }^{41}$ & 2012 & Colorectal cancer & 59 & $\begin{array}{l}\text { Lys, Ala, Asp, Gly, His, Leu/lle, Met, } \\
\text { Sarc, Thr, Tyr, Val } \downarrow\end{array}$ & $\begin{array}{l}\text { The significant alterations in the } \\
\text { amino acid profile in colon } \\
\text { cancer have promising } \\
\text { diagnostic power. }\end{array}$ \\
\hline Hasim et al. ${ }^{42}$ & 2013 & Cervical cancer & 22 & $\begin{array}{l}\text { Asp, Glu, Asn, Ser, Gly, His, Arg, } \\
\text { Thr, Tau, Tyr, Val, Met, Lys, Ile, Leu, } \\
\text { Phe } \downarrow\end{array}$ & $\begin{array}{l}\text { PFAA profiles may have the } \\
\text { potential for cancer diagnoses in } \\
\text { the early stage. }\end{array}$ \\
\hline Buijs et al. ${ }^{44}$ & 2010 & $\begin{array}{l}\text { Head and neck } \\
\text { cancer }\end{array}$ & 32 & $\begin{array}{l}\text { Arg may be a potential player in } \\
\text { the treatment of head and neck } \\
\text { cancer patients: perioperative } \\
\text { Arg-enriched enteral nutrition } \\
\text { improved the long-term overall } \\
\text { and disease-specific survival in } \\
\text { malnourished patients with head } \\
\text { and neck cancer }\end{array}$ & \\
\hline
\end{tabular}

Table 2. Connections between amino acids and different cancers

\begin{tabular}{|c|c|c|}
\hline $\mathrm{Gln} \downarrow$ & $\begin{array}{l}\text { Breast cancer }{ }^{29} \\
\text { Pancreatic } \text { cancer }^{27,38} \\
\text { Lung cancer }^{29} \\
\text { Gastric cancer }^{29} \\
\text { Colorectal cancer } \\
\text { Prostate cancer } \\
\text { P9 }\end{array}$ & $\begin{array}{l}\text { Cancer cells depend on Gln for tricarboxylic acid cycle intermediates, cellular energetics, reactive oxygen } \\
\text { species buffering, lipid synthesis, mTOR activity, and autophagy (which is inhibited by mTOR). }\end{array}$ \\
\hline Gly $\downarrow$ & $\begin{array}{l}\text { Breast cancer }{ }^{28,29} \\
\text { Pancreatic cancer } \\
\text { Colorectal cancer }^{27} \\
\text { Cervical cancer }\end{array}$ & $\begin{array}{l}\text { Gly consumption and its mitochondrial biosynthetic pathway are strongly correlated with cancer cell } \\
\text { proliferation. }\end{array}$ \\
\hline Ser $\downarrow$ & $\begin{array}{l}\text { Pancreatic } \text { cancer }^{27} \\
\text { Gastric cancer }^{28} \\
\text { Colorectal } \\
\text { cancer }^{21,27,42} \\
\text { Cervical cancer }^{43}\end{array}$ & Cancer cells consumed Ser to convert to intracellular Gly and one-carbon units for building nucleotides. \\
\hline BCAAs $\downarrow$ & $\begin{array}{l}\text { Breast cancer }{ }^{27} \\
\text { Pancreatic cancer }^{27} \\
\text { Gastric cancer }^{28} \\
\text { Colorectal cancer }^{30} \\
\text { Colonic cancer }\end{array}$ & The muscle wasting syndrome experience by many cancer patients decreased BCAAs levels. \\
\hline
\end{tabular}

consumption was pronounced in pancreatic cancer, ${ }^{27}$ breast cancer, ${ }^{28,29}$ colorectal cancer ${ }^{41}$ and cervical cancer. ${ }^{42}$ 'While Ser levels were high in some patients with pancreatic cancer, ${ }^{20}$ breast cancer, ${ }^{31,32}$ lung cancer, and colorectal cancer, ${ }^{29}$ probably due to the overexpression of phosphoglycerate dehydrogenase, other cancers, such as colorectal cancer, ${ }^{21,27,42}$ pancreatic cancer, ${ }^{27}$ gastric cancer ${ }^{28}$ and cervical cancer ${ }^{43}$ consumed Ser. Although Ser and Gly could be inter-converted and either of them might be used for one-carbon metabolism and nucleotide synthesis, convincing evidence suggested that cancer cell proliferation were supported by Ser instead of Gly consumption. Gly was believed to be a consequence of the rapid cell proliferation. ${ }^{60}$

It is well-known that the BCAAs have important roles in the maintenance of lean body mass and regulation of skeletal muscle 
Table 3. Associations between PFAAs and insulin resistance and T2D (from 2010 to 2016)

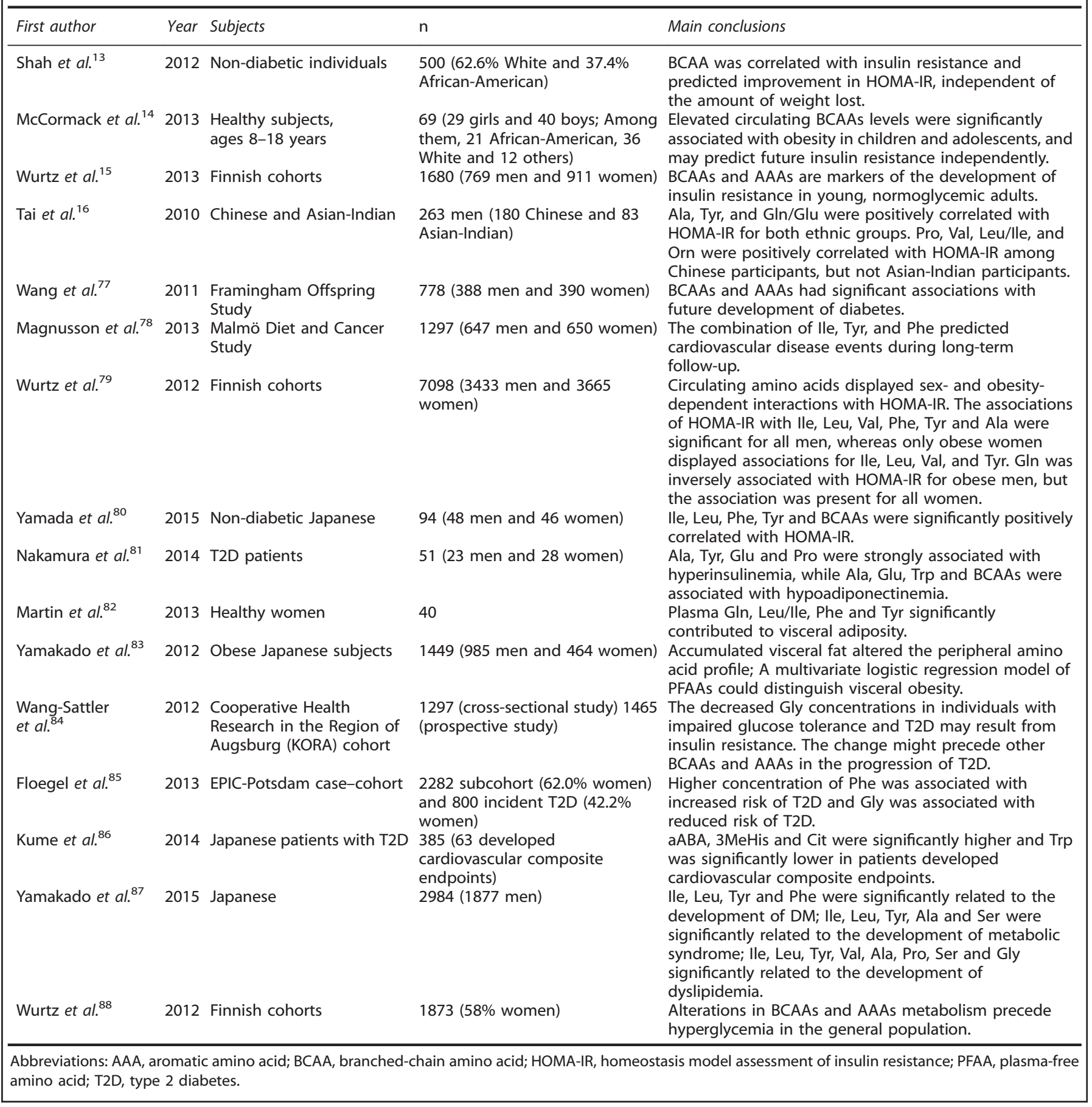

protein metabolism. Therefore, the investigation of BCAAs and their metabolites in the cancer-bearing state, where muscle wasting is a significant comorbidity, is of importance. Elevated plasma BCAAs levels have been observed to raise the risk of future diagnosis of pancreatic cancer by two-fold. ${ }^{61}$ The high BCAA concentrations were attributed to the enhanced whole-body protein breakdown in development of pancreatic ductal adenocarcinoma. Therefore, BCAA profiles could be used as a general marker to diagnose pancreatic ductal adenocarcinoma. In addition, the direct effects of BCAAs on cultured human hepatocellular carcinoma cells have also been reported previously. ${ }^{62}$ It was found that increased BCAAs levels suppressed the hepatocellular carcinoma cell lines proliferation. One of the plausible mechanisms underlying suppression of cancer cells by BCAAs was associated with their capability of inhibition of insulin signals through suppressing the expression of IGF. ${ }^{63}$ It is believed that insulin induced cell proliferation by activating the mitogenactivated protein kinase pathway. ${ }^{64}$ BCAAs have also been reported to accelerate mRNA degradation of insulin-induced vascular endothelial growth factor at the post transcriptional level, downregulating vascular endothelial growth factor expression during the hepatocellular carcinomas development. ${ }^{65}$ 
Furthermore, BCAAs were reported to induce the apoptosis of liver cancer cell lines by inhibiting insulin-induced phosphatidylinositol-3-kinase (PI3K)/Akt and the nuclear factor-kappa beta (NF-KB) signaling pathways through the mammalian target of rapamycin complex 1- (mTORC1) and complex 2- (mTORC2) dependent mechanisms. ${ }^{66}$

Some other amino acids, such as Tau, have been reported to decrease human cervical cancer cell proliferation in a dose- and time-dependent manner. ${ }^{67}$ It was also suggested that assessment of serum Tau levels in patients with high breast cancer risk was useful in the early diagnosis of malignant changes in breast. ${ }^{68}$ Additionally, plasma Arg levels were lower in patients with cancers, indicating that Arg metabolism may be disturbed in the presence of a malignancy. ${ }^{27,44,69}$ Although the metabolic changes of different cancers can determine their own unique PFAA profiles, the role of cancer-specific amino acids remains to be elucidated. Further studies are required to verify the significance of PFAA alterations in cancers development and management.

\section{ALTERED PFAA PROFILES IN DIABETES MELLITUS}

T2D is characterized by insulin resistance and/or impaired insulin secretion from beta cells. The prevalence of T2D is markedly increasing around the world and the rates of increase show no signs of slowing. ${ }^{70} \mathrm{~A}$ complete understanding of the pathophysiology of insulin resistance and T2D, or the identification of early stage metabolic alterations, is promising in the study of etiological pathways and may hold the potential to develop preventive strategies. A number of biomarkers, including fasting plasma glucose and glycated hemoglobinA1c, have been proposed as indicators for the estimation of T2D risk. ${ }^{71}$ Yet many populations from overweight to moderately obese have completely normal fasting plasma glucose and hemoglobinA1c, leaving them undiagnosed as pre-diabetics in spite of underlying dysfunctional metabolism. This highlights the fact that only considering glucose metabolism was not sufficient when determining the etiology and consequences of T2D. ${ }^{72}$

More and more metabolomics-based studies have consistently reported the perturbation of normal amino acid metabolism in insulin resistance and T2D in recent years. ${ }^{73}$ Multiple amino acids, particularly BCAAs, have been shown to be modulators of insulin secretion. ${ }^{74,75}$ Increasing evidence suggests that elevated plasma BCAAs levels may have adverse effects on the regulation of glucose homeostasis, because the oxidation of BCAAs spares glucose utilization in skeletal muscle. ${ }^{76}$ On the other hand, for individuals without significant abnormalities in glucose homeostasis, elevations in BCAAs levels, along with AAAs are also significantly associated with an increased future likelihood of developing $\mathrm{T}_{2} \mathrm{D}^{77}$ and cardiovascular diseases. ${ }^{78}$ One of the possible mechanisms by which hyperaminoacidemia could promote DM is via hyperinsulinemia leading to pancreatic beta cell exhaustion. The association between insulin resistance and increased circulating BCAAs levels were supported by several other studies with different ethnic groups and degree of obesity. ${ }^{12-14,16,79,80}$ Table 3 summarizes 16 recent studies reporting the associations between PFAA profiles and insulin resistance and $\mathrm{T} 2 \mathrm{D}$.

Shah et al. ${ }^{13}$ conducted a large randomized trial to understand health benefits occurring as a result of weight loss by using highthroughput metabolomic profiling. They found that BCAAs were unique to predict the improvement in HOMA-IR (homeostasis model assessment of insulin resistance), and suggested a potential mechanism for the heterogeneity in health benefits obtained from weight loss. The associations between BCAAs concentrations and adverse metabolic profiles were also observed in children and adolescents. It is noteworthy that the elevations in BCAAs may independently predict future insulin resistance in these participants. ${ }^{14}$ In the Framingham Offspring Study, BCAAs and AAAs were found to have significant relationships with future development of DM. ${ }^{77}$ The combination of three amino acids, that is, lle, Phe and Tyr, predicted future DM with a four- to six-fold increased risk for participants in top quartile. The combination of Ile, Phe and Tyr also helped to predict future cardiovascular diseases during a long-term follow-up, probably through increased tendency towards the development of atherosclerosis. $^{78}$ The plausible etiology of elevated BCAAs levels in obesity is through the suppression of BCAA catabolism by insulin resistance. ${ }^{11}$ It should be noted that, besides obesityassociated insulin resistance, BCAAs levels were also positively correlated with HOMA-IR in individuals with normal body mass. ${ }^{16,80}$ The underlying mechanisms between insulin resistance and elevated BCAAs are related with the persistent activations of mTORC and S6K1 as shown in Table 4.

Increased circulating levels of Phe and Tyr (or AAAs) have been reported to be associated with insulin resistant, $\mathrm{T} 2 \mathrm{D}$ or cardiovascular diseases states. ${ }^{77-80,82,84,87,88}$ The directionality of the blood concentration shifts of Phe and Tyr are usually the same because Tyr is the first product of Phe catabolism. In the studies using blood metabolites to predict $\mathrm{T}_{2} \mathrm{D}^{77}$ and determining correlations between metabolites and insulin sensitivity, ${ }^{89}$ Phe and Tyr provided some of the strongest associations. The positive correlation between Phe and/or Tyr and insulin secretion may be involved in pathways to compensate early stage of insulin resistance through stimulating insulin secretion (Table 4).

Contrary to BCAAs and AAAs, the relationships of other amino acids with insulin resistance remain incompletely understood. Nakamura et al. ${ }^{81}$ recruited 51 of patients with T2D and measured their PFAA profiles. They observed that the levels of Glu, Ala, Trp and BCAAs were inversely correlated with adiponectin concentrations. As adiponectin is very important in the regulation of insulin sensitivity and metabolism, it might be the cause of insulin resistance and change PFAA profiles in diabetic patients. They also found that the concentrations of Ala, Tyr, Glu and Pro were significantly correlated with fasting plasma insulin. There results indicated the strong association between PFAA profiles, circulating adiponectin concentration and insulin resistance; however, the

\begin{tabular}{ll}
\hline Table 4. & Connections between amino acids and insulin resistance \\
\hline Amino acids & Mechanisms \\
\hline BCAAs & $\begin{array}{l}\text { The elevated BCAAs are able to activate mTORC and its downstream effecter S6K1 in the liver, muscle and adipose tissue. Persistent } \\
\text { activation leads to serine phosphorylation of IRS-1 and thus the inhibition of IRS-1, resulting in insulin resistance. }\end{array}$ \\
AAAs & $\begin{array}{l}\text { AAAs are metabolized to catecholamines, which alter the liver function leading to hyperinsulinemia and dyslipidemia. } \\
\text { Met }\end{array}$ \\
Met metabolism may intersect with Phe/Tyr catabolism and stimulate insulin secretion. Its transmethylation to homocysteine to affect \\
glucose homeostasis.
\end{tabular}




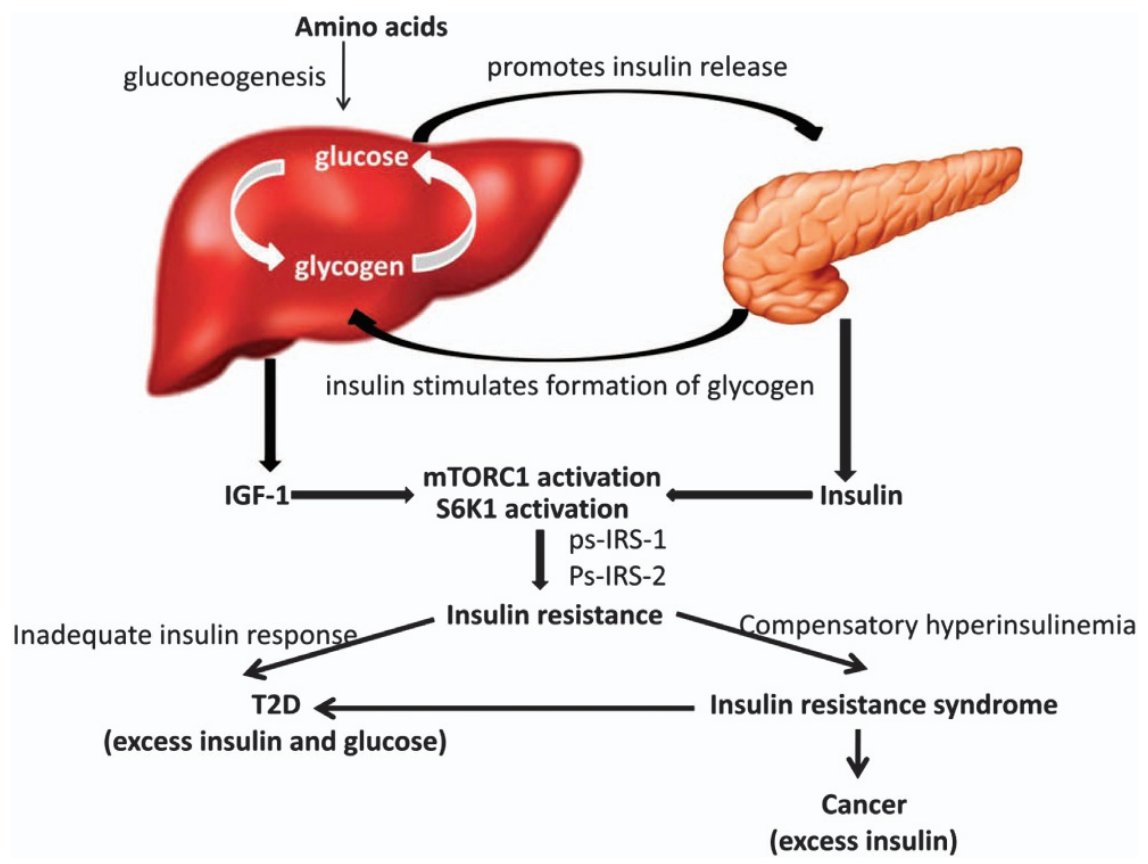

Figure 1. Mechanism of the link between insulin resistance, T2D and cancers. Amino acids metabolism in the liver via the gluconeogenic pathway increases glucose levels, which promotes insulin secretion from the pancreas. IGF-1 and insulin activate mTORC1 and S6K1. Persistent activation leads to serine phosphorylation of IRS-1 and IRS-2. The resulting insulin resistance increases demand on insulin to dispose of excess glucose. Long-term demand may negatively affect the function of islets, resulting in an inadequate insulin response and leading to the onset of T2D. On the other hand, some insulin resistant individuals who are able to maintain the degree of hyperinsulinemia needed to maintain normal (or near-normal) glucose tolerance are at increased risk of cancers. IGF-1, Insulin-like growth factor 1; IRS, insulin receptor substrate; mTORC1, mammalian target of rapamycin complex 1; S6K1, ribosomal protein S6 kinase $\beta 1$; T2D, type 2 diabetes.

underlying mechanism was unclear. Some other studies in healthy obese $^{82,83}$ and in pre-diabetic subjects ${ }^{84}$ suggested that the levels of Ala, Gly, Gln, Glu, Trp, Tyr and BCAAs were correlated with visceral adiposity which was associated with deregulated insulin signaling. However, in the EPIC-Potsdam case-cohort, ${ }^{85}$ increased concentration of Phe and reduced concentration of Gly were found to be independently predictive of T2D. Unlike Phe which stimulated insulin secretion, the depletion of Gly may reflect increased gluconeogenesis or glutathione consumption driven by

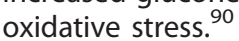

\section{CONCLUSIONS AND FUTURE DIRECTIONS}

This review has highlighted the potential use of the PFAA profiling as a novel diagnostic tool to access the risk of cancers and T2D. Results from epidemiological studies have suggested that obesity and $\mathrm{T} 2 \mathrm{D}$ are positively correlated with the increased risk of several cancers. The underlying link between obesity, T2D, and cancer is related to insulin resistance, hyperinsulinemia, and disturbances in IGF signaling systems (Figure 1). The insulin resistant state is correlated with a metabolic profile of altered metabolism of protein, which may affect the PFAA profiles. Looking at previous clinical data, the metabolic alterations of insulin resistance, T2D or cancers can determine their own unique PFAA profiles. Although PFAA alterations can be used for diagnosis of cancers or T2D with sufficient sensitivity and robustness, the specificity is low. The discrepancies exist between the results of previous studies due to the variations in participant characteristics, for example, age, gender, ethnic background, degree of obesity, diet, different techniques for amino acids measurement, different types and stages of cancers and limited size of data set.

Future research is needed to investigate the characteristic PFAA profiles to discriminate individual cancer types with different stages from healthy controls. Additional validation of the profiles using a larger sample size is necessary to establish the clinical utility. Furthermore, it is needed to elucidate the biological mechanisms by which amino acids might promote cancer risk and progression or T2D and its complications because the roles of insulin resistance or hyperinsulinemia or hyperglycemia in regulating the enzymes utilizing amino acids are still incompletely understood. Although our understanding of alterations in PFAAs metabolism in the diabetic or cancer states remains immature, we believe that PFAA profiling has the clinical usefulness for the detection of cancers or T2D.

On the other hand, while it is evident that Asian populations are more insulin resistant than other ethnic groups, in spite of less obesity, it is necessary to better identify the factors underlying the interethnic differences. As mentioned earlier, PFAA profiles have been utilized as biomarkers to detect cancers and diabetes. However, few studies have been investigated whether specific populations in Asia may have different PFAA profiles. To our best knowledge, only a few studies have been conducted in Asian populations, most of which are limited to Japanese. The rising prevalence of diabetes and cancers in Asia urgently need to clarify the associations of PFAA profiles with these diseases. These findings may provide new insight into how dietary or other interventions alter PFAA profiling in humans and to access whether these changes could ultimately improve metabolic health in cancer patients or pre-diabetes or T2D patients.

\section{CONFLICT OF INTEREST}

The authors declare no conflict of interest.

\section{ACKNOWLEDGEMENTS}

The authors greatly acknowledge the financial support from Singapore Institute for Clinical Sciences, Agency for Science, Technology, and Research (A*Star), Singapore. 


\section{REFERENCES}

1 Vigneri P, Frasca F, Sciacca L, Pandini G, Vigneri R. Diabetes and cancer. Endocr Relat Cancer 2009; 16: 1103-1123.

2 Giovannucci E, Harlan DM, Archer MC, Bergenstal RM, Gapstur SM, Habel LA et al. Diabetes and cancer: a consensus report. Diabetes Care 2010; 33: 1674-1685.

3 Joh HK, Willett WC, Cho E. Type 2 diabetes and the risk of renal cell cancer in women. Diabetes Care 2011; 34: 1552-1556.

4 Kahn SE, Hull RL, Utzschneider KM. Mechanism linking obesity to insulin resistance and type 2 diabetes. Nature 2006; 444: 840-846.

5 Solarek W, Czarnecka AM, Escudier B, Bielecka ZF, Lian F, Szczylik C. Insulin and IGFs in renal cancer risk and progression. Endocr Relat Cancer 2015; 22: R253-R264.

6 Savage DB, Petersen KF, Shulman Gl. Disordered lipid metabolism and the pathogenesis of insulin resistance. Physiol Rev 2007; 87: 507-520.

7 Muoio DM, Newgard CB. Mechanisms of diseases: molecular and metabolic mechanisms of insulin resistance and beta-cell failure in type 2 diabetes. Nat $\mathrm{Rev}$ Mol Cell Biol 2008; 9: 193-205.

$8 \mathrm{Kim}$ YS, Maruvada P, Milner JA. Metabolomics in biomarker discovery: future uses for cancer prevention. Future Oncol 2008; 4: 93-102.

9 Felig P, Marliss E, Cahill GF Jr. Plasma amino acid levels and insulin secretion in obesity. N Engl J Med 1969; 281: 811-816.

10 Costeas PA, Chinsky JM. Effects of insulin on the regulation of branched-chain alpha-keto acid dehydrogenase E1 alpha subunit gene expression. Biochem J 1996; 318: 85-92.

11 Lackey DE, Lynch CJ, Olson KC, Mostaedi R, Ali M, Smith WH et al. Regulation of adipose branched-chain amino acid catabolism enzyme expression and crossadipose amino acid flux in human obesity. Am J Physiol Endocrinol Metab 2013; 304: E1175-E1187.

12 Newgard CB, An J, Bain JR, Muehlbauer MJ, Stevens RD, Lien LF et al. A branched-chain amino acid-related metabolic signature that differentiates obese and lean humans and contributes to insulin resistance. Cell Metab 2009; 9: 311-326.

13 Shah SH, Crosslin DR, Haynes CS, Nelson S, Turer CB, Stevens RD et al. Branchedchain amino acid levels are associated with improvement in insulin resistance with weight loss. Diabetologia 2012; 55: 321-330.

14 McCormack SE, Shaham O, McCarthy MA, Deik AA, Wang TJ, Gerszten RE et al. Circulating branched-chain amino acid concentrations are associated with obesity and future insulin resistance in children and adolescents. Pediatr Obes 2013; 8: 52-61.

15 Wurtz $P$, Soininen $P$, Kangas AJ, Rönnemaa $T$, Lehtimäki $T$, Kähönen $M$ et al. Branched-chain and aromatic amino acids are predictors of insulin resistance in young adults. Diabetes Care 2013; 36: 648-655.

16 Tai ES, Tan MLS, Stevens RD, Low YL, Muehlbauer MJ, Goh DLM et al. Insulin resistance is associated with a metabolic profile of altered protein metabolism in Chinese and Asian-Indian men. Diabetologia 2010; 53: 757-767.

17 Wang TJ, Larson MG, Vasan RS, Cheng S, Rhee EP, McCabe E et al. Metabolite profiles and the risk of developing diabetes. Nat Med 2011; 17: 448-453.

18 Engelen MP, Wouters EF, Deutz NE, Menheere PP, Schols AM. Factors contributing to alterations in skeletal muscle and plasma amino acid profiles in patients with chronic obstructive pulmonary disease. Am J Clin Nutr 2000; 72: 1480-1487.

19 Zhang Q, Takahashi M, Noguchi Y, Sugimoto T, Kimura T, Okumura A et al. Plasma amino acid profiles applied for diagnosis of advanced liver fibrosis in patients with chronic hepatitis C infection. Hepatol Res 2006; 34: 170-177.

20 Fukutake N, Ueno M, Hiraoka N, Shimada K, Shiraishi K, Saruki N et al. A novel multivariate index for pancreatic cancer detection based on the plasma free amino acid profile. PLoS One 2015; 10: e0132223.

21 Yatabe J, Yatabe MS, Ishibashi K, Nozawa Y, Sanada H. Early detection of colon cancer by amino acid profiling using Aminolndex Technology: a case report. Diagn Pathol 2013; 8: 203.

22 Noguchi $Y$, Zhang QW, Sugimoto T, Furuhata Y, Sakai R, Mori M et al. Network analysis of plasma and tissue amino acids and the generation of an amino index for potential diagnostic use. Am J Clin Nutr 2006; 83: 513S-519S.

23 Huang J, Plass C, Gerheauser C. Cancer chemoprevention by targeting the epigenome. Curr Drug Targets 2011; 12: 1925-1956.

24 Stattin P, Bylund A, Rinaldi S, Biessy C, Dechaud H, Stenman UH et al. Plasma insulin-like growth factor-1, insulin-like growth factor-binding proteins, and prostate cancer risk: a prospective study. J Natl Cancer Inst 2000; 92: 1910-1917.

25 Burroughs KD, Dunn SE, Barrett JC, Taylor JA. Insulin-like growth factor-1: a key regulator of human cancer risk. J Natl Cancer Inst 1999; 91: 579-581.

26 Proenza AM, Oliver J, Palou A, Roca P. Breast and lung cancer are associated with a decrease in blood cell amino acid content. J Nutr Biochem 2003; 14: 133-138.

27 Vissers YL, Dejong CH, Luiking YC, Fearon KC, Meyenfeldt MF, Deutz NE. Plasma arginine concentrations are reduced in cancer patients: evidence for arginine deficiency?. Am J Clin Nutr 2005; 81: 1142-1146.
28 Gu Y, Chen T, Fu S, Sun X, Wang L, Wang J et al. Perioperative dynamics and significance of amino acid profiles in patients with cancer. J Transl Med 2015; 13 : 35.

29 Miyagi Y, Higashiyama M, Gochi A, Akaike M, Ishikawa T, Miura T et al. Plasma free amino acid profiling of five types of cancer patients and its application for early detection. PLoS One 2011; 6: e24143.

30 Okamoto N, Miyagi Y, Chiba A, Akaike M, Shiozawa M, Imaizumi A et al. Diagnostic modeling with differences in plasma amino acid profiles between non-cachectic colorectal/breast cancer patients and healthy individuals. Int J Med Med Sci 2009; 1: 1-8.

31 Poschke I, Mao Y, Kiessling R, Boniface J. Tumor-dependent increase of serum amino acid levels in breast cancer patients has diagnostic potential and correlates with molecular tumor subtypes. J Transl Med 2013; 11: 290.

32 Barnes T, Bell K, DiSebastiano KM, Vance V, Hanning R, Russell C et al. Plasma amino acid profiles of breast cancer patients early in the trajectory of the disease differ from healthy comparison groups. Appl Physiol Nutr Metab 2014; 39: 740-744.

33 Nagata C, Wada K, Tsuji M, Hayashi M, Takeda N, Yasuda K. Plasma amino acid profiles are associated with biomarkers of breast cancer risk in premenopausal Japanese women. Cancer Causes Control 2014; 25: 143-149.

34 Shingyoji M, lizasa T, Higashiyama M, Imamura F, Saruki N, Imaizumi A et al. The significance and robustness of a plasma free amino acid (PFAA) profile-based multiplex function for detecting lung cancer. BMC Cancer 2013; 13: 77.

35 Zhao Q, Cao Y, Wang Y, Hu C, Hu A, Ruan L et al. Plasma and tissue free amino acid profiles and their concentration correlation in patients with lung cancer. Asia Pac J Clin Nutr 2014; 23: 429-436.

$36 \mathrm{Kim} \mathrm{HJ}$, Jang SH, Ryu JS, Lee JE, Kim YC, Lee MK et al. The performance of a novel amino acid multivariate index for detecting lung cancer: a case control study in Korea. Lung Cancer 2015; 90: 522-527.

37 Schrader H, Menge BA, Belyaev O, Uhl W, Schmidt WE, Meier JJ. Amino acid malnutrition in patients with chronic pancreatitis and pancreatic carcinoma. Pancreas 2009; 38: 416-421.

38 Kobayashi T, Nishiumi S, Ikeda A, Yoshie T, Sakai A, Matsubara A et al. A novel serum metabolomics-based diagnostic approach to pancreatic cancer. Cancer Epidemiol Biomarkers Prev 2013; 22: 571-579.

$39 \mathrm{Ma} \mathrm{H}$, Hasim A, Mamtimin B, Kong B, Zhang HP, Sheyhidin I. Plasma free amino acid profiling of esophageal cancer using high-performance liquid chromatography spectroscopy. World J Gastroenterol 2014; 20: 8653-8659.

40 Zhang J, Bowers J, Liu L, Wei S, Gowda GA, Hammoud Z et al. Esophageal cancer metabolite biomarkers detected by LC-MS and NMR methods. PLoS One 2012; 7: e30181.

41 Leichtle AB, Nuoffer JM, Ceglarek U, Kase J, Conrad T, Witzigmann H et al. Serum amino acid profiles and their alterations in colorectal cancer. Metabolomics 2012; 8: 643-653.

42 Hasim A, Aili A, Maimaiti A, Mamtimin B, Abudula A, Upur H. Plasma-free amino acid profiling of cervical cancer and cervical intraepithelial neoplasia patients and its application for early detection. Mol Biol Rep 2013; 40: 5853-5859.

43 Ihata $\mathrm{Y}$, Miyagi E, Numazaki R, Muramatsu T, Imaizumi A, Yamamoto $\mathrm{H}$ et al. Amino acid profile index for early detection of endometrial cancer: verification as a novel diagnostic marker. Int J Clin Oncol 2014; 19: 364-372.

44 Buijs N, van Bokhorst-de van der Schueren MA, Langius JA, Leemans CR, Kuik DJ, Vermeulen MA et al. Perioperative arginine-supplemented nutrition in malnourished patients with head and neck cancer improves long-term survival. Am J Clin Nutr 2010; 92: 1151-1156.

45 Maeda J, Higashiyama M, Imaizumi A, Nakayama T, Yamamoto H, Daimon T et al. Possibility of multivariate function composed of plasma amino acid profiles as a novel screening index for non-small cell lung cancer: a case control study. BMC Cancer 2010; 10: 690.

46 Okamoto N. Use of 'Aminolndex Technology' for cancer screening. Ningen Dock 2012; 26: 911-922.

47 Medina MA, Marquez J, Nunez de Castro I. Interchange of amino acids between tumor and host. Biochem Med Metab Biol 1992; 48: 1-7.

48 Marquez J, Sanchez-Jimenez F, Medina MA, Quesada AR, Nunez de Castro I. Nitrogen metabolism in tumor bearing mice. Arch Biochem Biophys 1989; 268: 667-675.

49 Cascino A, Muscaritoli M, Cangiano C, Coversano L, Laviano A, Ariemma S et al. Plasma amino acid imbalance in patients with lung and breast cancer. Anticancer Res 1995; 15: 507-510.

50 Medina MA. Glutamine and cancer. J Nutr 2001; 131: 2539S-2542S.

51 Chen L, Cui H. Targeting glutamine induces apoptosis: a cancer therapy approach. Int J Mol Sci 2015; 16: 22830-22855.

52 Warburg O, Wind F, Negelein E. The metabolism of tumors in the body. J Gen Physiol 1927; 8: 519-530.

53 Korangath P, Teo WW, Sadik H, Han L, Mori N, Huijts CM et al. Targeting glutamine metabolism in breast cancer with aminooxyacetate. Clin Cancer Res 2015; 21: 3263-3273. 
54 Cheng T, Sudderth J, Yang C, Mullen AR, Jin ES, Mates JM et al. Pyruvate carboxylase is required for glutamine-independent growth of tumor cells. Proc Natl Acad Sci USA 2011; 108: 8674-8679.

55 Jain M, Nilsson R, Sharma S, Madhusudhan N, Kitami T, Souza AL et al. Metabolite profiling identifies a key role for glycine in rapid cancer cell proliferation. Science 2012; 336: 1040-1044.

56 Amelio I, Cutruzzola F, Antonov A, Agostini M, Melino G. Serine and glycine metabolism in cancer. Trends Biochem Sci 2014; 39: 191-198.

57 Zhang WC, Shyh-Chang N, Yang H, Rai A, Umashankar S, Ma S et al. Glycine decarboxylase activity drives non-small cell lung cancer tumor-initiating cells and tumorigenesis. Cell 2012; 148: 259-272.

58 Kim SK, Jung WH, Koo JS. Differential expression of enzymes associated with serine/ glycine metabolism in different breast cancer subtypes. PLoS One 2014; 9: 101004.

59 Possemato R, Marks KM, Shaul YD, Pacold ME, Kim D, Birsoy K et al. Functional genomics reveal that the serine synthesis pathway is essential in breast cancer. Nature 2011; 476: 346-350.

60 Labuschagne CF, van den Broek NJ, Mackay GM, Vousden KH, Maddocks OD. Serine, but not glycine, supports one-carbon metabolism and proliferation of cancer cells. Cell Rep 2014; 7: 1248-1258.

61 Mayers JR, Wu C, Clish CB, Kraft P, Torrence ME, Fiske BP et al. Elevation of circulating branched-chain amino acids is an early event in human pancreatic adenocarcinoma development. Nat Med 2014; 20: 1193-1198.

62 Sugiyama K, Yu L, Nagasue N. Direct effect of branched-chain amino acids on the growth and metabolism of cultured human hepatocellular carcinoma cells. Nutr Cancer 1998; 31: 62-68.

63 Iwasa J, Shimizu M, Shiraki M, Shirakami Y, Sakai H, Terakura Y et al. Dietary supplementation with branched-chain amino acids suppresses diethylnitrosamine-induced liver tumorigenesis in obese and diabetic C57BL/KsJ-db/ db mice. Cancer Sci 2010; 101: 460-467.

64 Formisano P, Oriente F, Fiory F, Caruso M, Miele C, Maitan MA et al. Insulinactivated protein kinase Cbeta bypasses Ras and stimulates mitogen-activated protein kinase activity and cell proliferation in muscle cells. Mol Cell Biol 2000; 20: 6323-6333.

65 Miuma S, Ichikawa T, Arima K, Takeshita S, Muraoka T, Matsuzaki T et al. Branchedchain amino acid deficiency stabilizes insulin-induced vascular endothelial growth factor mRNA in hepatocellular carcinoma cells. J Cell Biochem 2012; 113: 3113-3121.

66 Hagiwara A, Nishiyama M, Ishizaki S. Branched-chain amino acids prevent insulininduced hepatic tumor cell proliferation by inducing apoptosis through mTORC1 and mTORC2-dependent mechanisms. J Cell Physiol 2012; 227: 2097-2105.

$67 \mathrm{Kim}$ T, Kim AK. Taurine enhances anticancer activity of cisplatin in human cervical cancer cells. Adv Exp Med Biol 2013; 776: 189-198.

68 Agouza El, Eissa IM, SS, Houseini El, El-Nashar MM, Abd DE et al. A novel tumor marker for enhanced detection of breast cancer amnong female patients. Angiogenesis 2011; 14: 321-330.

69 Lind DS. Arginine and cancer. J Nutr 2004; 134: 2837S-2841S.

70 Wild S, Roglic G, Green A, Sicree R, King H. Global prevalence of diabetes: estimates for the year 2000 and projections for 2030. Diabetes Care 2004; 27: 1047-1053.

71 Peters AL, Davidson MB, Schriger DL, Hasselblad V. A clinical approach for the diagnosis of diabetes mellitus: an analysis using glycosylated hemoglobin levels. Meta-analysis research group on the diagnosis of diabetes using glycated hemoglobin levels. JAMA 1996; 276: 1246-1252.

72 Adams SH. Emerging perspectives on essential amino acid metabolism in obesity and the insulin-resistant state. Adv Nutr 2011; 2: 445-456.

73 Fiehn O, Garvey WT, Newman JW, Lok KH, Hoppel CL, Adams SH. Plasma metabolomic profiles reflective of glucose homeostasis in non-diabetic and type 2 diabetic obese African-American women. PLOS ONE 2010; 5: e15234.

74 Nilsson M, Holst JJ, Bjorck IM. Metabolic effects of amino acid mixtures and whey protein in healthy subjects: studies using glucose-equivalent drinks. Am J Clin Nutr 2007; 85: 996-1004.
75 Van Loon LJ, Saris WH, Verhagen H, Wagenmakers AJ. Plasma insulin responses after ingestion of different amino acid or protein mixtures with carbohydrate. Am J Clin Nutr 2000; 72: 96-105.

76 Buse MG, Biggers JF, Friderici KH, Buse JF. Oxidation of branched chain amino acids by isolated hearts and diaphragms of the rat. The effect of fatty acids, glucose, and pyruvate respiration. J Biol Chem 1972; 247: 8085-8096.

77 Wang TJ, Larson MG, Vasan RS, Cheng S, Phee EP, McCabe E et al. Metabolite profiles and the risk of developing diabetes. Nat Med 2011; 17: 448-454.

78 Magnusson M, Lewis GD, Ericson U, Orho-Melander M, Hedblad B, Engstrom G et al. A diabetes-predictive amino acid score and future cardiovascular disease. Eur Heart J 2013; 34: 1982-1989.

79 Wurtz P, Makinen VP, Soininen P, Kangas AJ, Tukiainen T, Kettunen J et al. Metabolic signatures of insulin resistance in 7098 young adults. Diabetes 2012; 61: 1372-1380.

80 Yamada C, Kondo M, Kishimoto N, Shibata T, Nagai Y, Imanishi T et al. Association between insulin resistance and plasma amino acid profile in non-diabetic Japanese subjects. J Diabetes Invest 2015; 6: 408-415.

81 Nakamura H, Jinzu H, Nagao K, Noguchi Y, Shimba N, Miyano H et al. Plasma amino acid profiles are associated with insulin, C-peptide and adiponectin levels in type 2 diabetic patients. Nutr Diabetes 2014; 4: e133.

82 Martin FPJ, Montoliu I, Collino S, Scherer M, Guy P, Tavazzi I et al. Topographical body fat distribution links to amino acid and lipid metabolism in healthy nonobese women. PLoS One 2013; 8: e73445.

83 Yamakado M, Tanaka T, Nagao K, Ishizaka Y, Mitushima T, Tani M et al. Plasma amino acid profile is associated with visceral fat accumulation in obese Japanese subjects. Clin Obes 2012; 2: 29-40.

84 Wang-Sattler R, Yu Z, Herder C, Messias AC, Floegel A, He Y et al. Novel biomarkers for pre-diabetes identified by metabolomics. Mol Syst Biol 2012; 8: 615.

85 Floegel A, Stefan N, Yu Z, Muhlenbruch K, Drogan D, Joost HG et al. Identification of serum metabolites associated with risk of type 2 diabetes using a targeted metabolomic approach. Diabetes 2013; 62: 639-648.

86 Kume S, Araki S, Ono N, Shinhara A, Muramatsu T, Araki H et al. Predictive properties of plasma amino acid profile for cardiovascular disease in patients with type 2 diabetes. PLoS One 2015; 9: e101219.

87 Yamakado M, Nagao K, Imaizumi A, Tani M, Toda A, Tanaka T et al. Plasma free amino acid profiles predict four-year risk of developing diabetes, metabolic syndrome, dyslipidemia, and hypertension in Japanese population. Sci Rep 2015; 5: 11918.

88 Wurtz P, Tiainen M, Makinen VP, Kangas AJ, Soininen P, Saltevo J et al. Circulating metabolite predictors of glycemia in middle-aged men and women. Diabetes Care 2012; 35: 1749-1756.

89 Huffman KM, Shah SH, Stevens RD, Bain JR, Muehlbauer M, Slentz CA et al Relationships between circulating metabolic intermediates and insulin action in overweight to obese, inactive men and women. Diabetes Care 2009; 32 : 1678-1683.

90 Sekhar RV, McKay SV, Patel SG, Guthikonda AP, Reddy VT, Balasubramanyam A et al. Glutathione synthesis is diminished in patients with uncontrolled diabetes and restored by dietary supplementation with cysteine and glycine. Diabetes Care 2011; 34: 162-167.

This work is licensed under a Creative Commons Attribution 4.0 International License. The images or other third party material in this article are included in the article's Creative Commons license, unless indicated otherwise in the credit line; if the material is not included under the Creative Commons license, users will need to obtain permission from the license holder to reproduce the material. To view a copy of this license, visit http://creativecommons.org/licenses/ by/4.0/

(c) The Author(s) 2017 